\title{
Treatment of Juvenile Myoclonic Epilepsy
}

\author{
Stéphane Auvin \\ 1 Department of Pediatric Neurology, Lille University Hospital, Lille, France \\ 2 EA 1046, Pharmacology Laboratory, Lille School of Medicine, Lille, France
}

\section{Keywords}

EEG; Generalized epilepsy; Myoclonic seizure;

Myoclonic epilepsy; Antiepileptic drugs.

\section{Correspondence}

Stéphane Auvin, M.D., Ph.D., Pediatric

Neurology Department, Hôpital Roger Salengro, 59037 Lille Cedex, France.

Tel.: +33-3-20-44-40-57;

Fax: +33-3-20-44-53-93;

E-mail: auvin@invivo.edu
Drug treatment of juvenile myoclonic epilepsy (JME) is mainly based on clinical experience and prospective and retrospective studies, with little evidence from randomized clinical trials. There are almost no head-to-head comparisons between old and new antiepileptic drugs (AEDs). Valproate is the drug of the first choice in men with JME. In women, lamotrigine (LTG) should be preferred regarding teratogenicity and side effects of valproate. Levetiracetam (LEV) is also effective. Recent data suggest that it may soon be used as first line treatment. Some AEDs can aggravate JME. In addition to AEDs, nonpharmacological treatments are important in JME. JME usually requires lifelong treatment because seizures nearly always return after withdrawal of therapy.

\section{Introduction}

Juvenile myoclonic epilepsy (JME) is an idiopathic generalized epilepsy (IGE) [1]. It is a collection of seizure patterns that are clinically distinct from those in other forms of IGE, with the major characteristic being adolescenceonset myoclonic seizures. Although the pathogenesis is unknown, recent advances, especially in genetics, suggest several possible mechanisms [2]. JME is both genetically and clinically heterogeneous; some clinical variations may indicate differences in pathogenesis. The nosology and classification of IGE syndromes are currently under revision $[3,4]$. JME is characterized by a particular pharmacological sensitivity. Valproate has historically been described to have a specific potency. Other antiepileptic drugs (AEDs) are also efficient, such as clonazepam (CZP), lamotrigine (LTG), levetiracetam (LEV), and topiramate (TPM), while others may have aggravating effect. There is a lack of adequate powered study for JME [5].

\section{Electroclinical Features of Juvenile Myoclonic Epilepsy}

JME is a common IGE characterized by myoclonic seizures. It is the most common IGE in adults, espe- cially in women. Isolated myoclonic jerks of the arms, especially shortly after awakening, are the characteristic feature. Generalized tonic-clonic seizures (GTCS) often occur, and one-third of individuals have absences. The GTCS are often preceded by a few minutes of generalized myoclonus of increasing frequency and intensity. They occur predominantly after awakening. Seizure occurrence is more likely related to sleep deprivation, fatigue, and alcohol withdrawal. Onset is usually in adolescence but seizures may begin or be diagnosed only in the early 20s. Eighty percent of patients with JME begin having seizures between ages 12 and 18 years. The mean age of onset for GTCS is 15.5 years. The most important element in the diagnosis of JME is the clinical history.

Misdiagnosis and delayed diagnosis remain common $[6,7]$. Patients frequently come to medical attention only after a GTCS, and the history of much earlier myoclonic jerks is then often obtained retrospectively [7].

The typical electroencephalographic abnormality is bilateral multiple spike or polyspike-wave complexes, which precede a myoclonic jerk. The EEG discharge includes 5-20 spikes with a frequency between 12 and $16 \mathrm{~Hz}$. The amplitude of spikes is frequently maximal in anterior areas. An ictal recording is best obtained by polygraphic video-EEG performing a provoked early morning awakening during a full-night sleep recording or at 
least after nocturnal sleep deprivation [8]. JME is one of the epileptic syndrome clearly associated with photosensitivity which occurs in about 30\% $[9,10]$. Myoclonic seizures can be induced by intermittent luminous stimulation in photosensitive patients, but clinical photosensitivity is less frequent than during EEG recording. In some cases, focal clinical or EEG features or both in patients with JME can be observed [11-15]. These features include not only unilateral myoclonic jerks but also version and asymmetrical tonic limb posturing. These focal features lead sometimes to a erroneous diagnosis of partial epilepsy. The misdiagnosis can also be responsible for the prescription of an AED aggravating JME.

JME is usually described as a benign condition because of its particular pharmacological sensitivity. However, a distinctive set of personality features (i.e., lack of drive and endurance, unsteadiness, unreliability, an unstable self-concept, and rapidly changing affect and mood states), have been early described [16]. These observations have been confirmed by other studies [17-19]. In a study involving $25 \mathrm{JME}$ patients and aged-match controls, JME sample exhibited twice the amount of psychiatric symptoms than age-matched norms. Furthermore, psychopathological symptoms increased with duration of JME [20]. The frequency of psychiatric disorders was also evaluated in 100 patients with JME and compared with healthy controls. Psychiatric disorders were more frequent in JME $(n=49)$. Anxiety and mood disorders were diagnosed in 23 and 19 patients, respectively. Moreover, the disorders were more frequently observed in patients with higher seizure frequency [21]. These reports may have implications for clinical care. The evaluation of psychopathological comorbidity should be considered as a necessary part of clinical assessment.

\section{Treatment}

The goal of management is to render the individual seizure-free without the side effect(s) of antiepileptic drug(s). JME more frequently requires lifelong treatment because seizures nearly always return after withdrawal of therapy [22,23]. Late seizure recurrence in treated patients seems to be leading to AED withdrawal or erratic life style [24]. JME is difficult to treat in about $15 \%$ of patients. The predictors of pharmacoresistance include: (i) the coexistence of all three seizure types (myoclonic jerks, absence seizures, and GTCS), (ii) the existence of associated psychiatric problems, and (iii) focal clinical symptoms and/or focal EEG discharges [25-27].

\section{Nonpharmacological Treatment}

In JME, lack of sleep and alcohol intake can induce seizures. The sleep-wake rhythm has to be regulated. The circumstances interfering with normal sleep and progressive awakening in the morning should be eliminated. If the patient stays up late at night, he should sleep longer in the next morning. Alcoholic drinks will only be permitted in small quantities, on social occasions. Patients should be advised not to drink in cases of lack of sleep. If the patient has photosensitivity, one should avoid relevant visual stimuli. Some maneuvers reduce the risk of photosensitive seizures, including monocular-complete occlusion, increased distance from a video-display terminal, and the provision of ambient back lighting [28]. We suggest these approaches to patients who show photosensitivity on EEG but do not know how successful these environmental alterations are in JME.

\section{Valproate}

Valproic acid (VPA) is a branched-chain fatty acid that markedly differs in structure from all other AED in clinical use. Its mechanism of action remains not fully understood. There are evidences that VPA increases GABA concentrations, the mechanism by which this occurs remains unknown. Multiple mechanisms have been proposed, including inhibition of GABA-T action, activation of GABA synthesis by an increase of GAD activity, and increased release of GABA into the synapse.

Based on clinical experience, VPA was first proposed as a treatment of myoclonic seizures. Twenty-three years ago, the sensitivity of JME to VPA was reported [22]. Although JME is an important syndrome, there have been almost no randomized clinical trials conducted using any medication for its treatment. However, there have been many open case studies conducted with VPA in JME management. The open series that have been published using VPA show a $41-88 \%$ seizure-free rate for patients receiving VPA, either as an add-on medication or as monotherapy [6,29]. Case studies have also shown that a low, once-daily dose (500 mg) of VPA can effectively control JME and keep patients seizure free for as long as 2 years $[30,31]$. Newer studies that examined the efficacy of LTG, TPM, and VPA in JME have all shown that VPA has the best efficacy of the three [32-35]. More recently, the SANAD study concluded for generalized epilepsy that VPA should remain the drug of first choice for many patients. The Standard and New Antiepileptic Drugs (SANAD) study was a randomized unblended controlled trial involving 716 patients. Three AED were compared: VPA, LTG, and TPM. This study suggested that VPA was more effective than LTG and had a better tolerance than TPM [36].

VPA is today one of the most effective AED in JME. It should be considered the first line drug, at least for men. Taking into account the teratogenicity (possibly lessened 
by the concurrent use of folic acid) and some side effects (weight gain), VPA is often considered unacceptable in young women of childbearing age.

\section{Benzodiazepin}

Benzodiazepines work by primarily enhancing gammaaminobutyric acid (GABA)ergic inhibition by binding to the benzodiazepine receptor on GABAA receptors [37].

CZP can also be effective in the treatment of JME. Obeid et al. treated 17 JME patients with CZP [38]. All of them had myoclonic seizures before treatment, and 14 of the 17 had GTCS before treatment. After CZP treatment, myoclonic seizures were controlled in $15(88 \%)$ of 17 patients, and the remaining two patients had a $75 \%$ reduction in seizure frequency. However, CZP did not produce effective results for reducing GTCS. The GTCS of $6(43 \%)$ out of the 14 patients were controlled. In addition, two patients sustained injuries during GTCS because CZP eliminated their myoclonic seizures, which had served as a warning, and they went directly into a GTCS. The authors concluded that CZP, while effective in treating myoclonic seizures, probably should not be used to control GTCS.

\section{Lamotrigine}

LTG is a phenyltriazine derivative. LTG acts through inhibition of voltage-activated sodium channels and possibly calcium channels, so that it prevents the release of glutamate [39].

LTG is effective in controlling GTCS and absence while there are some reports of myoclonic seizures exacerbation [40,41].

Many studies performed over recent years have demonstrated clinical utility for the treatment of JME. An open-label study to evaluate LTG as an alternative to valproate (63 patients switched from valproate to LTG) demonstrated an improvement in $67 \%$ of patients. No aggravation of clinical symptoms was also reported [42]. Buchanan conducted a study of 12 patients with JME who were treated with LTG monotherapy [43]. Five $(41 \%)$ of these 12 patients became seizure free while receiving LTG monotherapy, and the authors concluded that LTG might be effective in the management of JME. In a retrospective study, VPA monotherapy $(\mathrm{n}=36)$ and LTG monotherapy $(\mathrm{n}=14)$ were compared, as well VPA $(\mathrm{n}=22)$, LTG $(\mathrm{n}=21)$, and TPM polytherapy $(\mathrm{n}=15)$ were compared. The results suggested that LTG were an effective option as monotherapy and polytherapy [34]. Furthermore, the efficacy of LTG in JME was evaluated in bitherapy. The polytherapy is especially interesting in case of drug resistance. The combination of LTG with VPA appears synergistic in many types of epilepsy. However, the same combination is lead to an increased risk to develop a rash $[44,45]$. LTG monotherapy is usually described as AED that is not associated with an increased risk for major fetal malformation in most of the available studies $[46,47]$. The data from the UK Epilepsy and Pregnancy Register suggested a positive dose-reponse relationship for malformations in LTG monotherapy, particularly at doses higher than $200 \mathrm{mg} /$ day [48].

\section{Levetiracetam}

LEV is a pyrrolidone derivative, and is the S-enantiomer of the ethyl analogue of piracetam. While the exact mechanism of action of LEV is not known, it appears to act via a specific binding site within the brain (but neither directly affect GABA or glutamate nor alter sodium channel properties), produces a limited reduction in highvoltage-activated calcium currents, and possibly modulates intracellular calcium transients [49,50]. Molecular studies involving transgenic mice suggest that LEV binds to a synaptic vesicle protein (SVA2) that is involved in vesicle neurotransmitter exocytosis, and that the binding affinity to SVA2 is directly proportional to seizure protection [51].

LEV is probably the best new AED in the treatment of JME and may replace VPA for the treatment of the disorder because of high and sustained efficacy, fast action, and an excellent safety profile. Preliminary safety data in human pregnancy suggest that LEV did not frequently induce major congenital malformations. Using a UK pregnancy register, 117 pregnancies exposed to LEV were analyzed. Three of them had major congenital malformations $(2.7 \%$; $95 \%$ CI: 0.9-7.7). All three were exposed to other AEDs. Further study need to confirm this result [52].

The recent data suggest that it can be used as first line treatment. Noachtar et al. evaluated LEV in 122 patients (113 with JME and 9 with juvenile absence epilepsy). This study was a double-bind multicenter placebo controlled trial conducted in patients without control on one AED. The responder rate was $58.3 \%$ with LEV versus $23.3 \%$ with placebo [53]. Specchio et al. conducted a multicenter, prospective open-label study in patients with JME [54]. Ten patients had newly diagnosed and 38 had refractory resistant and/or were intolerant to previous AED. Five dropped out. Eighteen $(37.5 \%)$ had myoclonia control and $35(73 \%)$ had no GTCS.

More recently, two studies evaluated efficacy and tolerability of LEV monotherapy. Verrotti et al. reported 32 JME patients treated by LEV as first administered drug. At 6-month evaluation, 15 patients were seizure free; 14 patients were responders $(>50 \%$ reduction 
in seizures) while 29 patients were seizure free after 12 months of treatment. No patients reported adverse events [55]. In a retrospective study, Scharpe et al. registered 12 patients with LEV as the first therapy and 16 as the initial appropriate agent. Eighty percent (24/30) of patients became seizure free with LEV monotherapy and two additional patients showed improved seizure control. Treatment failure with VPA also did not predict failure of LEV [56].

Finally, LEV was evaluated as effective and welltolerated drug for treating GTCS in patients with IGE. Berkovic et al. conducted a multicenter, randomized, double-blind, placebo-controlled study of 164 patients (LEV, $\mathrm{n}=80$; placebo, $\mathrm{n}=84$ ), including 54 patients with JME ( $\mathrm{n}=24$ in LEV group, $\mathrm{n}=30$ in placebo group). LEV produced a greater mean reduction in GTCS frequency per week over the treatment period $(56.5 \%)$ than placebo $(28.2 \%)$. The percentage of patients who had $>50 \%$ reduction of GTCS frequency per week (responders) during the treatment period was $72.2 \%$ for LEV and $45.2 \%$ for placebo (OR: 3.28; 95\% CI: 1.68-6.38). The percentage of patients free of GTCS (34.2\% vs. $10.7 \%)$ and all seizure types $(24.1 \%$ vs. $8.3 \%$ ) was also greater for LEV than placebo. LEV was well tolerated with $1.3 \%$ of patients discontinuing therapy [57].

\section{Topiramate}

TPM is a sulphamate-substituted monosaccharide that exhibits some inhibition of carbonic anhydrase. Its AED activity is independent of this effect. TPM has multiple modes of action, including modulation of voltagedependent sodium channels, potentiation of GABAergic inhibition at a novel site on the GABAA receptor, and possible action at non-Nmethyl- D-aspartate (NMDA) receptors [58-60].

Several studies have shown the usefulness of TPM in patients with JME. There is one randomized-controlled study on the efficacy of TPM in patients with GTCS including patients with JME [61]. A reduction of more than $50 \%$ of GTCS were reported in $8 / 11$ patients treated by TPM compare to $2 / 11$ in placebo-treated patients. A reduction in myoclonic and absence seizures was also reported but did not achieve statistical significance. TPM efficacy and tolerability were evaluated in 22 patients with JME [62]. Sixteen patients completed the first year of the follow-up, while four left the study because of poor seizure control and two because of low compliance. Myoclonic seizures were controlled in 11 patients and persisted in 5 patients. GTCS were completely controlled in 10 patients, 4 patients had more than $50 \%$ reduction of seizures and 2 had reduction less than $50 \%$. In a randomized open-label treatment, 28 patients with a recent diagnosed JME received TPM or VPA [63]. Twelve of 19 patients treated with TPM and 7 of 9 patients treated by VPA completed the study. Generalized tonic-clonic, myoclonic and absence seizures were totally controlled in $10 / 12,9 / 14$, and $2 / 2$ TPM-treated patients, respectively, and 3/4, 7/9 and 1/2 valproate-treated patients. In a retrospective cohort, TPM monotherapy and polytherapy were considered as an alternative to VPA [34].

\section{Zonisamide}

By blocking the voltage-sensitive sodium channels, zonisamide (ZNS) prevents repetitive neuronal firing. It also reduces voltage-dependent T-type calcium channels, facilitates dopaminergic and serotoninergic neurotransmission, weakly inhibits carbonic anhydrase and may protect neurones from free-radical damage, thereby stabilizing neuronal membranes [64,65].

Few studies focused on the effects of ZNS are available. A retrospective study analyzing 15 patients (monotherapy in 13 patients and added to valproate in 2 patients) reported a good control of seizures. About $69 \%, 62 \%$, and $38 \%$ were free for generalized tonic-clonic, myoclonic, and absence seizures, respectively. Side effects were reported in $20 \%$ of patients [66]. In a neurophysiological study of one patient, ZNS permits almost complete disappearance of generalized spike and wave discharges [67]. These data suggest the possible usefulness of this AED in JME.

\section{AED Aggravating JME}

It is now well known that AEDs can aggravate epilepsy. Phenytoin (PHT), carbamazepine (CBZ) and oxcarbazepine have shown to aggravate the myoclonic and absence seizures of JME and therefore should be avoided [68-70]. Genton et al. conducted a study with CBZ and PHT to determine the risk of seizure aggravation in 40 patients with JME [68]. In the CBZ group, 19 (68\%) of 28 patients had a seizure aggravation, usually affecting the myoclonic seizure, and only $6(21 \%)$ of 28 patients improved. In the PHT group, six $(38 \%)$ of 16 patients had a seizure aggravation, and only $2(12 \%)$ of 16 patients improved. Aggravation mostly was in the form of increased myoclonic jerks. The authors concluded that among commonly prescribed AED, CBZ appears to have the strongest aggravating potential in patients with JME, whereas the aggravating effect of PHT is less prominent.

There have been isolated series of reports indicating that LTG can exacerbate or aggravate myoclonic seizures. Biraben et al. reported four patients with JME receiving LTG therapy that experienced myoclonus seizure aggravation [40]. Carrazana et al. also found two patients 
with JME (2/24) developed dramatic exacerbation of myoclonus and two others $(2 / 24)$ had mild transient increases in morning myoclonus with LTG [41].

\section{Antiepileptic Drug Selection}

When presented with a patient with epilepsy, physicians should prescribe the medication that will effectively control the seizures yet not endanger the patient with adverse events or seizure aggravation. Although JME is an important syndrome, there have been no randomized clinical trials conducted using any medication for its treatment. Drug treatment of JME is mainly based on clinical experience and prospective and retrospective studies. There are almost no head-to-head comparisons between old and new AEDs [5].

The 2001 and 2005 expert consensus surveys on adult epilepsies [71,72] ranked valproate as the treatment of choice for IGE when the patient's sex was not specified. However, in the 2005 survey adult epilepsy, when it was specified that the patient was a woman, the experts rated LTG as treatment of choice. In the 2005 expert opinion and 2007 European expert opinion about pediatric epilepsy treatment, VPA and LTG were the for 15-yearold male with JME, while LTG was the only choice for 15 year-old female with JME $[73,74]$. ZNS was rated as high second line by the experts on pediatric epilepsy while European experts rate it as third-line reflecting lack of familiarity with this AED and it limited availability in Europe [74]. In the 2007 pediatric expert opinion, LEV was rated sometimes appropriate in both sexes reflecting the recent data [73]. This rating may reflect the recent studies on JME and IGE.

VPA is historically the drug of the first choice in men with JME. In women, in whom considerations of teratogenicity, weight gain, and polycystic ovary syndrome are relevant, other options include LEV, LTG, TPM, and perhaps ZNS. In patients with symptoms refractory to treatment with one drug, VPA associated with small doses of LTG is often an effective combination. Recent data suggest that LEV can be used as second-line but may also be used as first line treatment.

\section{Conflict of Interest}

The authors have no conflict of interest.

\section{References}

1. Proposal for revised classification of epilepsies and epileptic syndromes. Commission on classification and terminology of the international league against epilepsy. Epilepsia 1989;30:389-399.
2. Zifkin B, Andermann E, Andermann F. Mechanisms, genetics, and pathogenesis of juvenile myoclonic epilepsy. Curr Opin Neurol 2005;18:147-153.

3. Engel J, Jr.. A proposed diagnostic scheme for people with epileptic seizures and with epilepsy: Report of the ILAE Task Force on Classification and Terminology. Epilepsia 2001;42:796-803.

4. Andermann F, Berkovic SF. Idiopathic generalized epilepsy with generalized and other seizures in adolescence. Epilepsia 2001;42:317-320.

5. Glauser T, Ben-Menachem E, Bourgeois B, Cnaan A, Chadwick D, Guerreiro C, Kalviainen R, Mattson R, Perucca E, Tomson T. Evidence-based analysis of antiepileptic drug efficacy and effectiveness as initial monotherapy for epileptic seizures and syndromes. Epilepsia 2006;47:1094-1120.

6. Atakli D, Sozuer D, Atay T, Baybas S, Arpaci B. Misdiagnosis and treatment in juvenile myoclonic epilepsy. Seizure 1998;7:63-66.

7. Grunewald RA, Chroni E, Panayiotopoulos CP. Delayed diagnosis of juvenile myoclonic epilepsy. J Neurol Neurosurg Psychiatry 1992;55:497-499.

8. Labate A, Ambrosio R, Gambardella A, Sturniolo M, Pucci $\mathrm{F}$, Quattrone A. Usefulness of a morning routine EEG recording in patients with juvenile myoclonic epilepsy. Epilepsy Res 2007;77:17-21.

9. Loiseau P, Duche B. Epilepsie myoclonique juvenile. Rev Neurol 1990;146:719-725.

10. Janz D. Epilepsy with impulsive petit mal (juvenile myoclonic epilepsy). Acta Neurol Scand 1985;72:449459.

11. Lancman ME, Asconape JJ, Penry JK. Clinical and EEG asymmetries in juvenile myoclonic epilepsy. Epilepsia 1994;35:302-306.

12. Aliberti V, Grunewald RA, Panayiotopoulos CP, Chroni E. Focal electroencephalographic abnormalities in juvenile myoclonic epilepsy. Epilepsia 1994;35:297-301.

13. Usui N, Kotagal P, Matsumoto R, Kellinghaus C, Luders HO. Focal semiologic and electroencephalographic features in patients with juvenile myoclonic epilepsy. Epilepsia 2005;46:1668-1676.

14. Montalenti E, Imperiale D, Rovera A, Bergamasco B, Benna P. Clinical features, EEG findings and diagnostic pitfalls in juvenile myoclonic epilepsy: A series of 63 patients. J Neurol Sci 2001;184:65-70.

15. Baise-Zung C, Guilhoto LM, Grossmann RM. Juvenile myoclonic epilepsy: Non-classic electroencephalographical presentation in adult patients. Eur J Neurol 2006;13:171-175.

16. Janz D, Christian W. Impulsive-Petit Mal. Dtsch Z Nervenheilkd 1957;170:346-386.

17. Gélisse P, Genton P, Samuelian JC, Thomas P, Bureau M. Psychiatric disorders in juvenile myoclonic epilepsy. Rev Neurol (Paris) 2001;157:297-302.

18. Trinka E, Kienpointner G, Uterberger I, Luef G, Bauer G, Doering LB, Doering S. Psychiatric comorbidity in 
juvenile myoclonic epilepsy. Epilepsia 2006;47:2086-2091.

19. Perini G, Tosin C, Carraro C, Bernasconi G, Canevini MP, Canger R, Pellegrini A, Testa G. Interictal mood and personality disorders in temporal lobe epilepsy and juvenile myoclonic epilepsy. J Neurol Neurosurg Psychiatry 1996;61:601-605.

20. Plattner B, Pahs G, Kindler J, Williams RP, Hall RE, Mayer H, Steiner H, Feucht M. Juvenile myoclonic epilepsy: A benign disorder? Personality traits and psychiatric sympoms. Epilepsy Behav 2007;10:560-564.

21. De Araujo Filho G, Pascalicchio TF, Da Silva Sousa P, Lin K, Ferreira Guilhoto L, Yacubian E. Psychiatric disorders in juvenile myoclonic epilepsy: A controlled study of 100 patients. Epilepsy Behav 2007;10:437-441.

22. Delgado-Escueta A, Enrile-Bascal F. Juvenile myoclonic epilepsy of Janz. Neurology 1984;34:285-294.

23. Baruzzi A, Procaccianti G, Tinuper P, Lugaresi E. Antiepileptic drug withdrawal in childhood epilepsies: Preliminary results of a prospective study. In:Faienza C, Prati GL, editors. Diagnostic and therapeutic problems in pediatric epileptology. Amsterdam, Elsevier, pp 1998;117-123.

24. Sokic D, Ristic A, Vojvodic N, Jankovic S, Sindjelic A. Frequency, causes, phenomenology of late seizure recurrence in patient with juvenile myoclonic epilepsy after a long period of remission. Seizure;2007; 16:533-537.

25. Fernando-Dongas MC, Radtke RA, VanLandingham KE, Husain AM. Characteristics of valproic acid resistant juvenile myoclonic epilepsy. Seizure 2000;9:385-388.

26. Gelisse P, Genton P, Thomas P, Rey M, Samuelian JC, Dravet C. Clinical factors of drug resistance in juvenile myoclonic epilepsy. J Neurol Neurosurg Psychiatry 2001;70:240-243.

27. Dasheiff RM, Ritaccio AL. Characterization of intractable juvenile myoclonic epilepsy: New perspectives on primarily generalized seizures. Seizure 1993;2:11-19.

28. Harding W, Jeavons J. Therapy. In: Harding W, Jeavons J, editors. Photosensitive Epilepsy. London:MacKeith Press, 1992;125-150.

29. Kleveland G, Engelsen B. Juvenile myoclonic epilepsy: Clinical characteristics, treatment and prognosis in a Norwegian population of patients. Seizure 1998;7:31-38.

30. Panagariya A, Sureka R, Ardana V. Juvenile myoclonic epilepsy - an experience from north western India. Acta Neurol Scand 2001;104:12-16.

31. Karlovassitou-Koriari A, Alexiou D, Angelopoulos P, Armentsoudis P, Dimitrakoudi E, Delithanasis I, Hamlatzis P, Baloyannis S. Low dose sodium valproate in the treatment of juvenile myoclonic epilepsy. J Neurol 2002;249:396-399.

32. Mohanraj R, Brodie M. Pharmacological outcomes in newly diagnosed epilepsy. Epilepsy Behav 2005;6:382-387.

33. Nicolson A, Appelton R, Chadwick D, Smith D. The relationship between treatment with valproate, lamotrigine, and topiramate and the prognosis of idiopathic generalised epilepsies. J Neurol Neurosurg Psychiatry 2004;75:75-79.

34. Prasad A, Kuzniecky R, Knowlton R, Welty T, Martin R, Mendez M, Faught R. Evolving antiepileptic drug treatment in juvenile myoclonic epilepsy. Arch Neurol 2003;60:1100-1105.

35. Mohanraj R, Brodie M. Outcomes of newly diagnosed idiopathic generalized epilepsy syndromes in a non-pediatric setting. Acta Neurol Scand 2007; 115:204-208.

36. Marson AG, Al-Kharusi AM, Alwaidh M, Appleton R, Baker GA, Chadwick DW, Cramp C, Cockerell OC, Cooper PN, Doughty J. The SANAD study of effectiveness of valproate, lamotrigine, or topiramate for generalised and unclassifiable epilepsy: An unblinded randomised controlled trial. Lancet 2007;369:1016-1026.

37. Rudolph U, Crestani F, Benke D, Brunig I, Benson J, Fritschy J, Martin J, Bluethmann H, Mohler H. Benzodiazepine actions mediated by specific gamma-aminobutyric acid(A) receptor subtypes. Nature 1999;401:796-800.

38. Obeid T, Panayiotopoulos CP. Clonazepam in juvenile myoclonic epilepsy. Epilepsia 1989;30:603-606.

39. Lees G, Leach MJ. Studies on the mechanism of action of the novel anticonvulsant lamotrigine (Lamictal) using primary neurological cultures from rat cortex. Brain Res 1993;612:190-199.

40. Biraben A, Allain H, Scarabin J, Schuck S, Edan G. Exacerbation of juvenile myoclonic epilepsy with lamotrigine. Neurology 2000;55:1758.

41. Carrazana E, Wheeler S. Exacerbation of juvenile myoclonic epilepsy with lamotrigine. Neurology 2001;56:1424-1425.

42. Morris G, Hammer A, Kustra R, Messenheimer J. lamotrigine for patients with juvenile myoclonic epilepsy following prior treatment with valproate: Results of an open-label study. Epilepsy Behav 2004;5:509-521.

43. Buchanan N. The use of lamotrigine in Juvenile Myoclonic Epilepsy. Seizure 1996;5:149-151.

44. Pisani F, Oteri G, Russo M, Di Perri R, Perruca E, Richens A. The efficacy of valproate-lamotrigine comedication in refractory complex partial seizures: Evidence for a pharmacodynamic interaction. Epilepsia 1999;40:1141-1146.

45. Gerike C, Picard F, Saint-Martin A, Strumina S, Marescaux C, Hirsch E. Efficacy of lamotrigine in idiopathic generalized epilepsy syndromes: A video-EEG-controlled open study. Epileptic Disord 1999;1:159-165.

46. Wide K, Winbladh B, Kallen B. Major malformations in infants exposed to antiepileptic drugs in utero, with emphasis on carbamazepine and valproic acid: A nation-wide, population-based register study. Acta Paediatr 2004;93:174-176. 
47. Meador KJ, Baker GA, Finnell RH, Kalayjian LA, Liporace JD, Loring DW, Mawer G, Pennell PB, Smith JC, Wolff MC. In utero antiepileptic drug exposure: Fetal death and malformations. Neurology 2006;67:407-412.

48. Morrow J, Russell A, Guthrie E, Parsons L, Robertson I, Waddell R, Irwin B, McGivern RC, Morrison PJ, Craig J. Malformation risks of antiepileptic drugs in pregnancy: A prospective study from the UK Epilepsy and Pregnancy Register. J Neurol Neurosurg Psychiatry 2006;77:193-198.

49. Zona C, Niespodziany I, Marchetti C, Klitgaard H, Bernardi G, Margineanu DG. Levetiracetam does not modulate neuronal voltage-gated $\mathrm{Na}^{+}$and T-type $\mathrm{Ca}^{2+}$ currents. Seizure;2001;10:279-286.

50. Herdon HJ, Jerman JC, Stean TO, Middlemiss DN, Chan WN, Vong AK, Evans JM, Thompson M, Upton N. Characterization of the binding of [3H]-SB-204269, a radiolabelled form of the new anticonvulsant SB-204269, to a novel binding site in rat brain membranes. $\mathrm{Br} J$ Pharmacol 1997;121:1687-1691.

51. Lynch BA, Lambeng N, Nocka K, Kensel-Hammes P, Bajjalieh SM, Matagne A, Fuks B. The synaptic vesicle protein SV2A is the binding site for the antiepileptic drug levetiracetam. Proc Natl Acad Sci U S A 2004;101:9861-9866.

52. Hunt S, Craig J, Russell A, Guthrie E, Parsons L, Robertson I, Waddell R, Irwin B, Morrow J. Levetiracetam in pregancy: Preliminary experience from UK Epilepsy and Pregnancy Register. Neurology 2006;67:1876-1879.

53. Noachtar S, Andermann E, Meyvisch P, Andermann F, Gough WB, Schiemann-Delgado J. Levetiracetam for the treatment of idiopathic generalized epilepsy with myoclonic seizures. Neurology 2008;70:607-616.

54. Specchio L, Gambardella A, Giallonardo A, Michelucci R, Specchio N, Boero G, La Neve A. Open label, long-term, pragmatic study on levetiracetam in the treatment of juvenile myclonic epilepsy. Epilepsy Res 2006;71:3239.

55. Verrotti A, Cerminara C, Coppola G, Franzoni E, Parisi P, Iannetti $\mathrm{P}$, et al. Levetiracetam in juvenile myoclonic epilepsy: Long-term efficacy in newly diagnosed adolescents. Dev Med Child Neurol 2008;50:29-32.

56. Sharpe DV, Patel AD, bou-Khalil B, Fenichel GM. Levetiracetam monotherapy in juvenile myoclonic epilepsy. Seizure;2008;17:64-68.

57. Berkovic SF, Knowlton RC, Leroy RF, Schiemann J, Falter U. Placebo-controlled study of levetiracetam in idiopathic generalized epilepsy. Neurology 2007;69:1751-1760.

58. White H, Brown S, Woodhead J, Skeen G, Wolf H. Topiramate modulates GABA-evoked currents in murine cortical neurons by a nonbenzodiazepine mechanism. Epilepsia 2000;41(Suppl. 1):17-20.
59. Zona C, Ciotti MT, Avoli M. Topiramate attenuates voltage-gated sodium currents in rat cerebellar granule cells. Neurosci Lett 1997;231:123-126.

60. Hanaya R, Sasa M, Ujihara H, Ishihara K, Serikawa T, Iida K, Akimitsu T, Arita K, Kurisu K. Suppression by topiramate of epileptiform burst discharges in hippocampal CA3 neurons of spontaneously epileptic rat in vitro. Brain Res 1998;789:274-282.

61. Biton V, Bourgeois B, YTC/YTCE study investigators. Topiramate in patients with juvenile myoclonic epilepsy. Arch Neurol 2005;62:1705-1708.

62. Sousa Pda S, Araujo Fihlo G, Garzon E, Sakamoto A, Yacubian E. Topiramate for the treatment of juvenile myoclonic epilepsy. Arq Neuropsquiatr 2005;63:733-737.

63. Levisohn PM, Holland KD. Topiramate or valproate in patients with juvenile myoclonic epilepsy: A randomized open-label comparison. Epilepsy Behav 2007;10:547-552.

64. Kito M, Maehara M, Wanatabe K. Mechanisms of T-type channel blockade by zonisamide. Seizure 1996;5:115-119.

65. Suzuki S, Kawakami K, Nishimura S, Watanabe Y, Yagi K, Seino M, Miyamoto K. Zonisamide blocks T-type channel in cultured neurons of rat cerebral cortex. Epilepsy Res 1992;12:21-27.

66. Kothare S, Valencia I, Khurana D, Hardison H, Melvin J, Legido A. Efficacy and tolerability of zonisamide in juvenile myoclonic epilepsy. Epileptic Disord 2004;6:267-270.

67. Szaflarski J. Effects of zonisamide on the electroencephalogram of a patient with juvenile myoclonic epilepsy. Epilepsy Behav 2004;5:1024-1026.

68. Genton P, Gelisse P, Thomas P, Dravet C. Do carbamazepine and phenytoin aggravate juvenile myoclonic epilepsy? Neurology 2000;55:1 106-1 109.

69. Thomas P, Valton L, Genton P. Absence and myoclonic status epilepticus precipitated by antiepileptic drugs in idiopathic generalized epilepsy. Brain 2006;129 (Pt 5):1281-1292.

70. Gelisse P, Genton P, Kuate C, Pesenti A, Baldy-Moulinier $\mathrm{M}$, Crespel A. Worsening of seizures by oxcarbazepine in juvenile idiopathic generalized epilepsies. Epilepsia 2004;45:1282-1286.

71. Karceski S, Morrell M, Carpenter D. The expert consensus guideline series: Treatment of epilepsy. Epilepsy Behav 2001;2(Suppl.):A1-A50.

72. Karceski S, Morrell MJ, Carpenter D. Treatment of epilepsy in adults: Expert opinion, 2005. Epilepsy Behav 2005;7(Suppl. 1):S1-64.

73. Wheless JW, Clarke DF, Arzimanoglou A, Carpenter D. Treatment of pediatric epilepsy: European expert opinion, 2007. Epileptic Disord 2007;9:353-412.

74. Wheless JW, Clarke DF, Carpenter D. Treatment of pediatric epilepsy: Expert opinion, 2005. J Child Neurol 2005;20:Suppl 1:S1-56. 